\title{
Genetic control of plastidic L-glutamate dehydrogenase isozymes in the genus Capsella (Brassicaceae)
}

\author{
HERBERT HURKA* \& SABINE DÜRING \\ University of Osnabrück, Faculty of Biology/Chemistry, Botany, Barbarastr. 11, D-49069 Osnabrück, Germany
}

\begin{abstract}
Leaf extracts of three Capsella species (Brassicaceae), two diploids and one tetraploid, have been analysed for isozymes of L-glutamate dehydrogenase on polyacrylamide gels. A plastidic GDH (EC 1.4.1.4.) consisted of at least seven bands. Progeny analyses and crossing experiments revealed that within the two diploid species two genetic loci code for this pattern. One of the loci, $G d h I$, appeared to be monomorphic. The other locus $G d h 2$, is polymorphic and segregates for three alleles determining allozymes in accordance with Mendelian inheritance. Estimates of outcrossing rates based on segregation at the $G d h 2$ locus support the view that one of the diploid species is highly inbred whereas the other is an obligate outbreeder. In the tetraploid species, both loci are apparently duplicated so that four instead of two genes determine the polypeptide structure of plastidic GDH. These loci share the same alleles with the diploid species and no additional allozymes have been detected.
\end{abstract}

Keywords: Capsella, GDH, gene duplication, isozyme loci, polymorphism, subcellular location.

\section{Introduction}

Glutamate dehydrogenase, GDH, EC 1.4.1.2-4, has been found in almost all types of organisms. In higher plants, organ and tissue specificity as well as subcellular location have been studied, indicating that GDH is present in different plant tissues and that it occurs in mitochondria, plastids and the cytosol (Stewart et al., 1980; Srivastava \& Singh, 1987 for reference). The enzyme GDH catalyses the reversible conversion of 2-oxoglutarate and L-glutamate. There are three forms of GDH with different coenzyme specificity $\left(\mathrm{NAD}^{+}-\right.$ $\mathrm{GDH}, \mathrm{EC}$ 1.4.1.2.; $\mathrm{NAD}^{+}\left(\mathrm{P}^{+}\right)-\mathrm{GDH}, \mathrm{EC}$ 1.4.1.3.; $\mathrm{NADP}^{+}-\mathrm{GDH}$, E.C. 1.4.1.4.). The $\mathrm{NAD}^{+}$-linked GDH has been described in general as the mitochondrial form and the $\mathrm{NADP}^{+}$-linked as the chloroplast enzyme. However, both enzymes can use both coenzymes, $\mathrm{NAD}^{+}$and $\mathrm{NADP}^{+}$. Therefore, coenzyme specificity as such cannot be used as a marker for subcellular localization.

In higher plants the GDH is a homohexameric enzyme (Stewart et al., 1980; Loulakis \& RoubelakisAngelakis, 1990, 1991; Bhadula \& Shargool, 1991). Electrophoresis on polyacrylamid gels (PAGE) often

*Correspondence. reveals a seven or even more banded pattern (Srivastava \& Singh, 1987 for reference). Its subcellular location and the underlying genetics have not been clearly resolved. Two genes are thought to be responsible for the polypeptide structure of GDH. This, however, has to be further substantiated as genetic analyses are almost lacking.

This paper provides evidence that in the genus Capsella (Brassicaceae) an overall GDH zymogram from leaf extract is of different subcellular origin, plastidic and extraplastidic. The zymograms of both GDH fractions were multiple banded. Two genetic loci in the diploid Capsella species code for the plastidic patterns. One locus appeared to be monomorphic whereas the other locus is polymorphic and segregates for three determining allozymes. In the tetraploid species, both genes are duplicated.

\section{Materials and methods}

\section{Plant material}

Investigations were carried out on the plants raised from seeds collected individually in the wild covering a wide geographical area (samples from Finland, Germany, Greece, Italy, Norway, Spain, Switzerland 
and the U.S.A.). All plants were grown in the greenhouse. Leaves of single plants were harvested and stored at $-80^{\circ} \mathrm{C}$. Plant material included the two diploid species $(2 n=2 \mathrm{x}=16)$ Capsella grandiflora (Fauché \& Chaub.) Boissier and Capsella rubella Reuter and the tetraploid species $(2 n=4 \mathrm{x}=32)$ Capsella bursa-pastoris (L.) Medicus.

\section{Native PAGE}

All steps were performed at $4^{\circ} \mathrm{C}$. Extracts were prepared from $1 \mathrm{~g}$ leaves of single plants. The leaves were homogenized in $0.5-1 \mathrm{ml}$ ice-cold extraction buffer containing $0.16 \mathrm{M}$ Tris- $\mathrm{HCl} ; \mathrm{pH} 8.0 ; 0.107 \mathrm{M}$ glycin. The extract was filtered through four layers of mull and centrifuged for $20 \mathrm{~min}$ at $39,000 \mathrm{~g}$. The supernatant was stored at $-80^{\circ} \mathrm{C}$. Then $60 \mu \mathrm{l}$ extract of each sample was loaded on a native 5.5 per cent PA gel with gel buffer $0.375 \mathrm{M}$ Tris- $\mathrm{HCl}, \mathrm{pH} 8.8$, and electrode buffer $0.125 \mathrm{M}$ Tris-borate, $\mathrm{pH}$ 8.9. Electrophoresis was performed at $75 \mathrm{~V}$ for $5-6 \mathrm{~h}$. The gels were equilibrated in $100 \mathrm{ml}$ staining solution containing $0.015 \mathrm{M}$ Tris- $\mathrm{HCl}, \mathrm{pH} 8.5,53 \mathrm{mM}$ L-glutamate, $0.8 \mathrm{mM}$ $\mathrm{NAD}^{+}, 0.3 \mathrm{mM}$ NBT. After $30 \mathrm{~min}, 0.08 \mathrm{mM}$ PMS was added and the gels were stained over-night in the dark (Dowerg, 1990). The gels have been preserved and routinely photographed.

\section{Subcellular fractionation}

All steps were performed at $4^{\circ} \mathrm{C}$. The crude extract was prepared as described by Walker $(1980)$ with some modifications for Capsella: $10 \mathrm{~g}$ leaves were extracted in $300 \mathrm{ml}$ ice-cold buffer A ( $330 \mathrm{mM}$ sorbitol, $25 \mathrm{mM}$ MES, pH 6.5, $5 \mathrm{mM} \mathrm{MgCl}_{2}, 5$ per cent PVP, 0.2 per cent BSA). The leaves were dissolved in an Ultra Turrax $\mathrm{T}$ $25(3 \times 5 \mathrm{~s})$. The extract was filtered through eight layers mull and one layer miracloth and centrifuged in a swing-out rotor at $7500 \mathrm{~g}$ for $1 \mathrm{~min}$. The pellets were resuspended in $10-15 \mathrm{ml}$ buffer $\mathrm{B}(330 \mathrm{mM}$ sorbitol, $50 \mathrm{mM}$ HEPES, pH 7.8, 4 mM EDTA, $2 \mathrm{mM} \mathrm{MgCl}$, $2 \mathrm{mM} \mathrm{MnCl}_{2}, 0.2$ per cent BSA) and underlayered with $10 \mathrm{ml} 40$ per cent Percoll in buffer B. This gradient was centrifuged for $2 \mathrm{~min}$ at $4000 \mathrm{~g}$. The chloroplast pellet was resuspended and washed again with $10-15 \mathrm{ml}$ buffer B for $2 \mathrm{~min}$ at $2500 \mathrm{~g}$. The enzyme activity of the crude extract and of the chloroplast fraction were tested with marker enzymes. The cytosolic marker enzyme was UDP-glucose pyrophosphorylase (UDPGLc-PPiase), EC 2.7.7.9 (Bergmeyer, 1979). Fumarase, EC 4.2.1.2, was the mitochondrial marker enzyme (Hill \& Bradshaw, 1983) and NADPglyceraldehyd-3-phosphatedehydrogenase (NADPGAPDH), EC 1.2.1.13, was used to identify the chloroplast fraction (Winter et al., 1982). Protein was estimated by the method of Bradford (1976).

\section{Results}

\section{Subcellular localization of $G D H$}

Differential centrifugation separated the crude extract from Capsella leaves into a plastidic and an extraplastic fraction. The chloroplast-containing fraction was identified by marker enzymes. Neither the mitochondrial nor the cytosolic marker enzyme could be detected in this specific fraction, only NADP-GAPDH activity was recorded (Table 1). From the comparison of the electrophoretic pattern of the crude extract with that of the chloroplast fraction, it was evident that the most cathodic banding pattern was of chloroplast origin.

\section{Genetics of the plastidic GDH in Capsella rubella}

All individuals assayed (more than 400) displayed a seven-banded plastidic GDH pattern. The fastest (most anodal) band always appeared in the same position on the gel. This is the reference band with $\mathrm{Rf}=100$ (internal standard). The slowest (most cathodal) band was found at two positions, at $\mathrm{Rf}=52$ and $\mathrm{Rf}=64$ (Fig. 1).

Progeny analyses revealed the true breeding nature of these seven-banded patterns clearly indicating that two genes rather than two different alleles of one gene are involved (Table 2). One gene $(G d h l)$ is fixed in all individuals at position $\mathrm{Rf}=100$ which refers to allele 1 , thus giving the genotype Gdh1-11. The other gene $(G d h 2)$ is polymorphic, allele $l$ at position $\mathrm{Rf}=52$ and allele 2 at position $R f=64$. Genotypes coding for the only two observed GDH patterns in Capsella rubella are, therefore, Gdh1-11 Gdh2-11 and Gdh1-11 Gdh2-22 (Fig. 1, Table 2). No heterozygotes were detected so far.

Table 1 Enzyme activities of marker enzymes specific for the cytosol (a), mitochondria (b), and chloroplast (c) measured in leaf extracts of Capsella rubella

Activity (units/mg of protein)

Crude extract Chloroplast fraction

\begin{tabular}{lll}
\hline (a) UDPGLc-PPiase & 0.069 & 0 \\
(b) Fumarase & 0.046 & 0 \\
(c) NADP-GAPDH & 0.033 & 0.024 \\
\hline
\end{tabular}




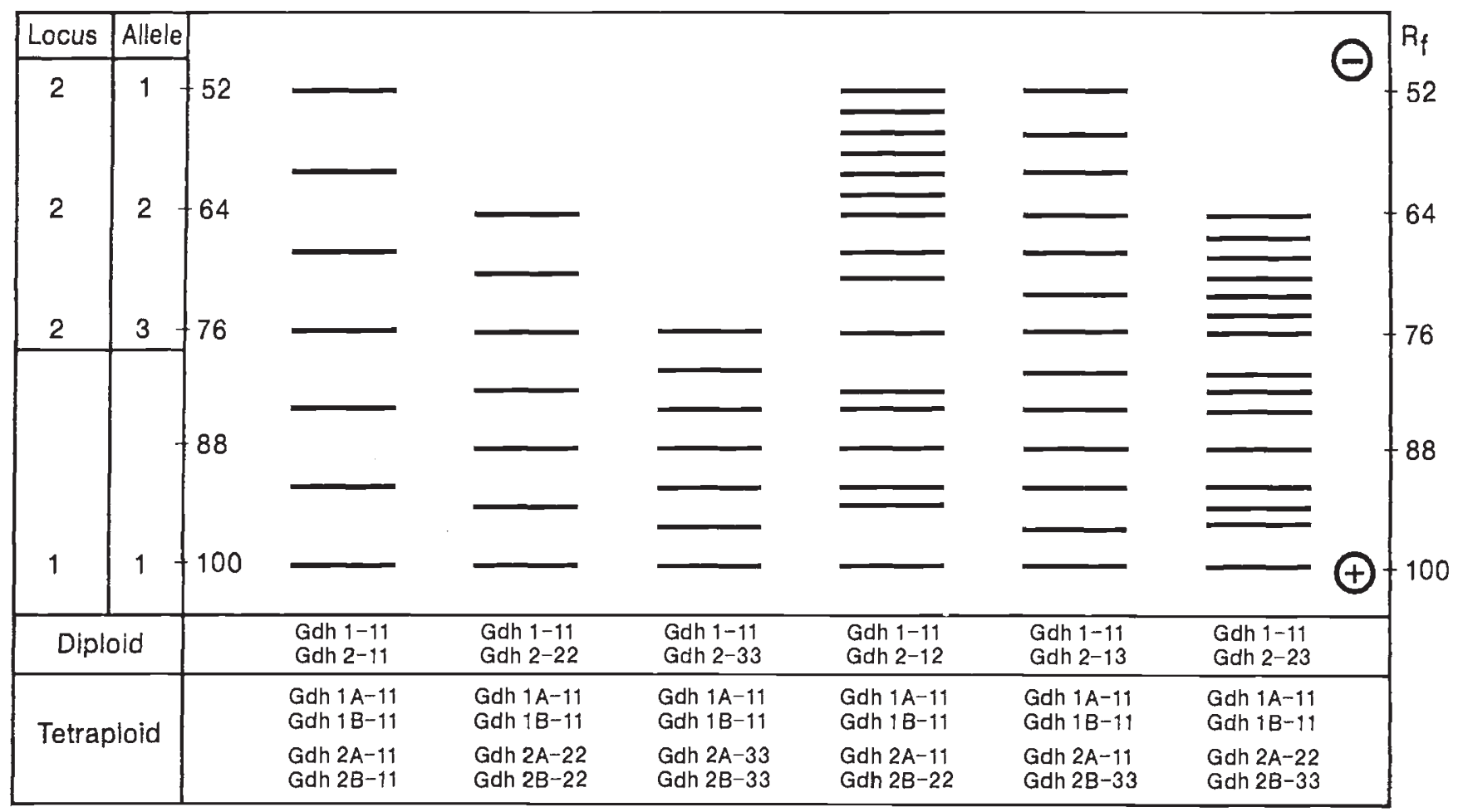

Fig. 1 GDH zymograms (schematic diagrams) for diploid and tetraploid Capsella species and their genetic interpretations.

Table 2 Progeny analyses for the plastidic GDH complex in Capsella rubella

\begin{tabular}{llll}
\hline Parent genotypes & $N$ & Progeny genotypes & $N$ \\
\hline Gdh1-11 Gdh2-11 & 6 & Gdhl-11 Gdh2-11 & 58 \\
Gdh1-11 Gdh2-22 & 3 & Gdh1-11 Gdh2-22 & 25 \\
\hline
\end{tabular}

\section{Genetics of plastidic GDH in Capsella grandiflora}

All individuals analysed (more than 700 ) had a multiple banded plastidic GDH pattern with seven bands being the minimum number. Thus, as in $C$. rubella, evidence is provided for two genetic loci. Judged by the equal electrophoretic mobility of the allozymes of $C$. rubella and C. grandiflora, the $G d h$ loci in $C$. grandiflora are homologous to those in C. rubella. Gdhl was fixed for allele $I$ as in $C$. rubella giving the genotype GdhI-II for all individuals. The Gdh2 locus in $C$. grandiflora had three alleles, two in common with $C$. rubella and one in addition. Crossing experiments corroborated the existence of the three alleles and their Mendelian inheritance (Table 3). Heterozygotes are frequent in natural populations of $C$. grandiflora, which suggests that outcrossing is common. Progeny analyses performed with a number of parent plants collected from natural populations further substantiated Mendelian segregation at the $G d h 2$ locus and proved
Table 3 Inheritance of Gdh2 genotypes in Capsella grandiflora. $G d h l$ is fixed for the same allele giving the genotype $G d h 1-11$ for all plants

\begin{tabular}{|c|c|c|c|}
\hline \multirow[b]{2}{*}{ Crossings } & & \multicolumn{2}{|c|}{$F_{1}$ genotypes } \\
\hline & & Observed & Expected \\
\hline \multirow{3}{*}{$G d h 2-12 \times G d h 2-12$} & $G d h 2-11$ & 5 & 4 \\
\hline & $G d h 2-12$ & 8 & 8 \\
\hline & Gdh2-22 & 3 & 4 \\
\hline \multirow[t]{2}{*}{$G d h 2-11 \times G d h 2-13$} & $G d h 2-11$ & 8 & 8.5 \\
\hline & $G d h 2-13$ & 9 & 8.5 \\
\hline \multirow[t]{2}{*}{$G d h 2-22 \times G d h 2-23$} & $G d h 2-22$ & 20 & 16 \\
\hline & $G d h 2-23$ & 12 & 16 \\
\hline
\end{tabular}

outbreeding within the natural populations (Table 4). Outcrossing rates were estimated using methods outlined by Brown et al.(1975).

\section{Genetics of plastidic GDH in Capsella bursa-pastoris}

The genetic loci coding for the plastidic GDH in Capsella bursa-pastoris are homologous to those in $C$. rubella and $C$. grandiflora which is evidenced by identical electrophoretic migration. As in the latter two species, $G d h l$ was also fixed in C. bursa-pastoris (more 
Table 4 Progeny analyses for Gdh2 in Capsella grandiflora and estimated outcrossing rates in different populations, $P=$ frequencies of allele 1 . In population 400 where three alleles occurred, alleles 1 and 3 are combined

\begin{tabular}{|c|c|c|c|c|c|c|}
\hline \multirow{4}{*}{$\begin{array}{l}\text { Accession } \\
\text { (Pop. No.) } \\
397\end{array}$} & \multicolumn{3}{|c|}{$\begin{array}{l}\text { Progeny geno- } \\
\text { types and } \\
\text { numbers }\end{array}$} & \multirow{2}{*}{\multicolumn{3}{|c|}{$\begin{array}{l}\text { Inferred mother genotype, } \\
\text { their numbers, and estimates } \\
\text { of outcrossing parameters }\end{array}$}} \\
\hline & \multirow{2}{*}{$\frac{11}{1}$} & \multirow{2}{*}{$\frac{12}{8}$} & \multirow{2}{*}{22} & & & \\
\hline & & & & 11 & 1 & $t=1.23 \pm 0.11$ \\
\hline & 7 & 31 & 28 & 12 & 7 & $P=0.27 \pm 0.03$ \\
\hline & - & 23 & 45 & 22 & 8 & \\
\hline 398 & - & - & - & 11 & 0 & $t=1.05 \pm 0.23$ \\
\hline & 11 & 30 & 16 & 12 & 6 & $P=0.41 \pm 0.08$ \\
\hline 400 & 12 & 5 & - & 11 & 2 & $t=0.59 \pm 0.15$ \\
\hline & 5 & 7 & 4 & 12 & 2 & $P=0.52 \pm 0.12$ \\
\hline & - & 6 & 14 & 22 & 2 & \\
\hline 421 & 9 & 10 & - & 11 & 2 & $t=1.11 \pm 0.15$ \\
\hline & 13 & 38 & 7 & 12 & 6 & $P=0.54 \pm 0.06$ \\
\hline & - & 15 & 14 & 22 & 6 & \\
\hline
\end{tabular}

Table 5 Progeny analyses for the $G d h 2$ complex of selfed Capsella bursa-pastoris plants. With regard to $G d h 1$, all plants were of the same genotype, Gdh1A-11 GdhlB-11

\begin{tabular}{|c|c|c|c|}
\hline Parent genotype & $N$ & Progeny genotype & $N$ \\
\hline$G d h 2 A-11 G d h 2 B-11$ & 14 & $G d h 2 A-11 G d h 2 B-11$ & 233 \\
\hline$G d h 2 A-22 G d h 2 B-22$ & 6 & $G d h 2 A-22 G d h 2 B-22$ & 129 \\
\hline$G d h 2 A-22 G d h 2 B-33$ & 8 & $G d h 2 A-22 G d h 2 B-33$ & 159 \\
\hline
\end{tabular}

than 3000 individuals checked). It appeared that in many samples the electrophoretic pattern was of the same phenotype as for heterozygotes $G d h 1-11 G d h$ 2-12 and Gdh1-11 Gdh2-23 in the diploid C. grandiflora (see Fig. 1). However, in contrast to C. grandiflora, these patterns did not segregate in progenies; they are true breeding ('fixed heterozygotes') (Table 5). All hybrid bands in the respective patterns are presumably of an interlocus origin and thus argue for gene duplication. The genotypic composition with regard to the plastidic $\mathrm{GDH}$ in $C$. bursa-pastoris is thus best described as Gdh1A-11 Gdh1B-11 Gdh $2 A-G d h 2 B-\ldots$ The numbering of loci and alleles corresponds with those in C. rubella and C. grandiflora (Fig. 1). Genotypes $G d h 2 A-11 G d h 2 B-22 ; G d h 2 A-22$ Ghd $2 B-33$; and $G d h 2 A-22 G d h 2 B-22$ were frequent within the total sample. Geographic variation was evident. The genotype $G d h 2 A-11 G d h 2 B-11$ was rare. The genotypes $G d h 2 A-11 G 2 B-33$ and $G d h 2 A-33 G d h 2 B-33$ have not been detected so far.

\section{Discussion}

Seven-banded electrophoretic patterns for GDH have been reported for many plants (Srivastava \& Singh, 1987). Gene analyses underlying these patterns, however, are few and ambiguous. Pryor (1974) studying the genetics of maize GDH isozymes suggested allelic variation at a single locus. However, banding patterns on starch gels were diffuse. Later, using polyacrylamide gels, seven-banded patterns from apparently homozygous inbred maize lines have been demonstrated by Sukhorzhevskaya et al. $(1976,1979,1980)$. This suggested the existence of a second $G d h$ gene, which was already proposed for pea by Pahlich in 1972 . Goodman \& Stuber (1982) have found variants of the Gdh2 gene in maize. Cammaerts \& Jacobs $(1983,1985)$ provided strong evidence for two structural $G d h$ genes in Arabidopsis thaliana, one of which apparently was polymorphic. The two genes seem to control the expression of enzymes with different metabolic functions. Ratajczak et al. (1986) based on immunological studies provided evidence for the existence of two 'subunits' composing the GDH pattern in pea. Loulakakis \& Roubelakis-Angelakis (1991) showed for Vitis vinifera that bands 1 and 7 within a seven-banded GDH pattern are homohexamers and bands 2-6 are hybrid molecules of the two homomeric polypeptides following an ordered ratio. This strongly argues for the existence of two structural genes coding for the GDH holozyme. However, the different ploidy levels of the plants studied were not taken into account which might have influenced the number of coding genetic loci. It would appear that at least two genetic loci code for organellar GDH for a number of higher plants.

The present study supports this conclusion. At least two genes code for plastidic GDH in the genus Capsella. The Gdhl gene locus seems to be fixed for the same allele in all three Capsella species studied whereas $G d h 2$ was polymorphic displaying up to three alleles. Progeny analyses revealed that $G d h 2$ is a nuclear gene. The location of $G d h 1$ remains unclear. There might be the possibility that this gene (or a related one in other taxa than Capsella) is of prokaryotic origin and is located on the chloroplast DNA. Bhadula \& Shargool (1991) reported GDH in the plastids of Glycine soja tissue cultures. When streptomycine was applied which blocks protein synthesis in the plastids, a significant decrease in total GDH amount was recorded evidencing that the major fraction of total GDH has been synthesized within the plastids. However, this does not necessarily mean that the blocked (prokaryotic) gene is located on chloroplast DNA. Whether one of these genes responsible for the seven-banded GDH pattern is actually prokaryotic 
and whether it is a chloroplast or a nuclear gene can only be revealed by appropriate DNA analyses.

In Capsella, Gdh2 is duplicated in the tetraploid species $C$. bursa-pastoris as revealed by the 'fixed heterozygotes' in the progeny array (Table 5). It is reasonable to assume that as an outcome of the polyploidization event $G d h$ l is also duplicated. It would be difficult to prove this duplication by isozyme electrophoresis as the locus $G d h 1$ is fixed for the same allozyme in all three Capsella species. One could suggest that the relative intensities of the isozymes might evidence the duplication. No attempt has been made to follow this possible line of evidence as GDH activities are known to be highly susceptible to environmental influences and proper experiments would be difficult. Nevertheless, the present study provides evidence that with polyploidization the number of genes coding for GDH is multiplied in Capsella, as it is with other isozymes.

Genetic variation at the $G d h 2$ complex appears to be a common feature in Capsella species. The number of different alleles detected in C. grandiflora (that is three) seems to exceed the number reported so far for other taxa (two in maize, two in Arabidopsis). Progeny analyses support the view that $C$. rubella is a highly inbred species and $C$. grandiflora is an obligate outbreeder (Hurka et al., 1989). With regard to C. bursapastoris, it was difficult to identify heterozygotes unambiguously due to overlapping of intra- and interlocus bands and due to an increase of a number of bands which often were not resolved accurately enough on the gels. However, heterozygotes were occasionally identified pointing to some proportion of outcrossing in the natural populations which fits the current view of breeding systems in C. bursa-pastoris (Hurka et al., 1989).

Newton in 1983 summarized the literature and came to the conclusion that the genetic basis and regulation of GDH isozymes is not yet understood for any higher plant'. This has changed since then, although little is known about genetic variation within species and about the evolution of the gene complex coding for the polypeptide structure of GDH.

\section{Acknowledgements}

We thank Dr A. H. D. Brown, CSIRO, Canberra, Australia, for discussions and help in estimation of mating system parameters, C. Desmarowitz, C. SunderPlaßmann and M. Wickenbrock for technical assistance. This work was supported by a grant of the Deutsche Forschungsgemeinschaft, DFG.

\section{References}

BERGMEYER, H. U. 1979. Methoden der enzymatischen Analyse. VCH, Weinheim.

BHADULA, S. K. AND SHARGOOL, P. D. 1991. A plastidial localization and origin of L-glutamate dehydrogenase in a soybean cell culture. Plant Physiol., 95, 258-263.

BRADFORD, M. M. 1976. A rapid and sensitive method for the quantitation of microgram quantities of protein utilizing the principle of protein-dye binding. Analyt. Biochem., 72, $248-257$

BROWN, A. H. D., MATHESON, A. C. AND ELDRIDGE, K. G. 1975. Estimation of the mating system of Eucalyptus obliqua L'Herit. by using allozyme polymorphisms. Aust. J. Bot., 23, 931-949.

CAMMAERTS, D. AND JACOBS, M. 1983. A study of the polymorphism and the genetic control of the glutamate dehydrogenase isozymes in Arabidopsis thaliana. Plant Sci. Lett., 31, 65-73.

CAMMAERTS, D. AND JACOBS, M. 1985. A study of the role of glutamate dehydrogenase in the nitrogen metabolism of Arabidopsis thaliana. Planta, 163, 517-526.

DOWERG, s. 1990. Subzelluläre Lokalisation von GlutamatDehydrogenase-Isoenzymen in der Gattung Capsella (Brassicaceae). Diploma Thesis, University of Osnabrück. GoOdman, M. M. AND STUBER, C. w. 1982. Localization of Gdh2 to chromosome 10. Maize Genet. Coop. Newsl., 56, 125.

HILL, R. A. AND BRADSHAW, R. A. 1983. Isolation of organelles from plant cells. In: Hall, J. L. and Moore, A. C. (eds) Biological Techniques, p. 178. Academic Press, New York. HURKA, H., FREUNDNER, S., BROWN, A. H. D. AND PLANTHOLT, U. 1989. Aspartate aminotransferase isoenzymes in the genus Capsella (Brassicaceae). Subcellular location, gene duplication and polymorphism. Biochem. Genet., 27, 77-90.

LOULAKAKIS, C. A. AND ROUBELAKIS-ANGELAKIS, K. A. 1990. Intracellular localization and properties of NADH-glutamate dehydrogenase from Vitis vinifera L.: Purification and characterization of the major leaf isoenzyme. J. Exp. Botany, 41, 1223-1230.

LOUlAKaKIS, K. A. AND ROUBELAKIS-ANGELAKIS, K. A. 1991. Plant $\mathrm{NAD}(\mathrm{H})$-glutamate dehydrogenase consists of two subunit polypeptides and their participation in the seven isoenzymes occurs in an ordered ratio. Plant Physiol., 97, 104-111.

NEWTON, K. J. 1983. Genetics of mitochondrial isozymes. In: Tanksley, S. D. and Orton, T. J. (eds) Isozymes in Plant Genetics and Breeding, part A, pp. 157-174. Elsevier, Amsterdam.

PAHLICH, E. 1972. Evidence that the multiple molecular forms of glutamate dehydrogenase from pea seedlings are conformers. Planta, 104, 78-88.

PRYOR, A. J. 1974. Allelic glutamic dehydrogenase isozymes in maize - a single hybrid isozyme in heterozygotes? Heredity, 32, 397-419.

RATAJCZAK, L. KORONIAK, D., MAZUROWA, H., RATAJCZAK, W. AND PRUS-GLOWACKI, W. 1986. Glutamate dehydrogenase isoforms in lupine roots and root nodules. Immunological studies. Physiol. Plant., 67, 685-689. 
SRIVASTAVA, H. S. AND SINGH, R. P. 1987. Role and regulation of L-glutamate dehydrogenase activity in higher plants. Phytochemistry, 26, 597-610.

STEWART, G. R., MANN, A. F. AND FENTEM, P. A. 1980. Enzymes of glutamate formation: glutamate dehydrogenase, glutamine synthetase, and glutamate synthase. In: Miflin, B. J. (ed.) The Biochemistry of Plants, vol. 5, pp. 271-327. Academic Press, London and New York.

SUKHORZHEVSKAYA, T. B. 1979. Organ-specific spectra of glutamate dehydrogenase in maize. (Zea mays L.). Sov. J. Dev. Biol., 9, 331-336.

SUKHORZHEVSKAYA, T. B. 1980. Investigation of genetic control over glutamate dehydrogenase in maize (Zea mays L.). Genetika, 16, 914-917.
SUKHORZHEVSKAYA, T. B., REIMERS, F. E. AND KHAVKIN, E. E. 1976. Multiple molecular forms of NAD-specific glutamate dehydrogenase in lines and hybrids of corn (Zea mays L.). Dokl. Biol. Sci, 227, 122-125.

WALKER, D. A. 1980. Preparation of higher plant chloroplasts. In: Colowick, S. P. and Kaplan, N. O. (eds) Methods in Enzymology, vol. 69. pp. 94-104. Academic Press, New York.

WINTER, K., FOSTER, J. G., EDWARDS, G. E. AND HOLTUM, J. A. M. 1982. Intracellular localization of enzymes of carbon metabolism in Mesembryanthemum crystallinum exhibiting C3-photosynthetic characteristics and performing crassulacean acid metabolism. Plant Physiol., 69, 300-307. 